\title{
A FORMAÇÃO DE UMA CONSCIÊNCIA SÓCIO AMBIENTAL, ATRAVÉS DA INTERPRETAÇÃO DE TRILHAS
}

\author{
Rudi Fernando dos Santos ${ }^{1}$, Paulo Edelvar Corrêa Peres ${ }^{2}$ \\ ${ }^{1}$ Biólogo, Especialista em Educação Ambiental - rudi_fernando@hotmail.com \\ ${ }^{2}$ Dr. Paulo Edelvar Corrêa Peres, professor orientador - pecperes@yahoo.com
}

\section{RESUMO}

As sociedades humanas sofreram um afastamento progressivo da natureza, um processo de autodestruição, onde se desencadeou uma verdadeira guerra com o meio ambiente. Para combater-se isso, deve-se alcançar um novo entendimento do indivíduo em relação ao meio ambiente, o que pode ser possível através da formação de uma consciência sócio ambiental mais justa, por meio da interpretação ambiental em práticas de trilhas, contextualizadas dentro das perspectivas da Educação Ambiental. O projeto fez uso de reflexões obtidas através do método dedutivo, adotando-se para a atividade de campo a metodologia de resgate/análise crítica, com a aplicação de trilhas guiadas e de interpretação da natureza. Tendo como sujeitos da pesquisa, 100 alunos do ensino médio da E. E. de E. M. Major Belarmino Côrtes, de Cruz Alta/RS. A área empregada situa-se na Estância Lara Gruhn, em Cruz Alta/RS, constituindo uma formação florestal representada por um fragmento de diferentes estruturas vegetais, circundados por lavouras e pastagem. Com 1.600 metros de extensão e duas horas de duração, a trilha foi considerada de baixo nível de dificuldade, onde de acordo com as respostas obtidas, pode-se perceber que as impressões positivas superaram as negativas. Constituindo-se dessa forma, de uma prática simples, que pode ser aplicada facilmente e que não necessita de altos investimentos, mas sim, de consciência e quebras de paradigmas, no sentido de se buscar novos hábitos sócio-culturais, os quais, auto-sustentáveis. Onde, a educação e a percepção despontam como mecanismos de defesa do meio natural, podendo contribuir para a tão necessária reaproximação do homem com natureza.

Palavras-chave: consciência; ambiental; trilhas.

\section{ABSTRACT}

Human societies have suffered a progressive separation of nature, a process of selfdestruction, where a veritable war with the environment. To combat this up, you should reach a new understanding of the individual in relation to the environment, it may be possible through the formation of a more just social and environmental awareness through the interpretation of tracks environmental practices, contextualized within the Perspectives of Environmental Education. The project made use of reflections obtained by the meth-deductive, adopting for the activity of field methodology for retrieval/review, with the application of guided trails and nature interpretation. The subjects of the study, 100 high school students of S. S. S. M. Major Bellarmine Court, Cruz Alta/RS. The area used is located in Estância Lara Gruhn, in Cruz Alta/RS, constituting a forest type represented by a fragment of different plant structures, surrounded by crops and pasture. With 1,600 meters long and two hours in length, the trail was considered a low level of difficulty, where according to the responses obtained, we can see that the positive impressions outnumbered negative. Constituting thus a simple practice that can be applied easily and does not require high in- 


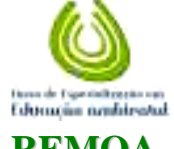

SANTOS \& PERES, vol.(4), nº, p. 568-581, 2011. Monografias Ambientais (e-ISSN: 2236-1308)

REMOA

vestments, but rather, conscience and breaks paradigms in order to seek new socio-cultural habits, which, self- sustainable. Where, education and perception appear as defense mechanisms of the natural environment and may contribute to the much-needed rapprochement between man and nature.

Keywords: conscience; environmental; tracks.

\section{INTRODUÇÃO}

O planeta Terra vive um período de intensas transformações técnico-científicas, em contrapartida das quais se engendram fenômenos de desequilíbrio ecológico e de considerável crescimento demográfico (GUATTARI, 2001).

Existindo duas realidades diferentes: uma organizada e estabelecida pela expansão das tecnologias digitais, e outra, pelo aumento grandioso da fome, violência, pobreza e miséria (MORAES, 2005), gravemente evidenciadas pela falta de conhecimento, assim como, pela falta de consciência ambiental (BERNA, 2001).

Interagindo com os sistemas naturais desde o início de seu surgimento, o homem sofreu um afastamento progressivo da natureza (MATAREZI et al., 2003), um processo de autodestruição acelerado pela revolução industrial no século XVIII, onde se desencadeou uma verdadeira guerra contra o meio ambiente (GUTIÉRREZ \& PRADO, 2000). Revolução essa, que visava além da produção em grande escala, o acúmulo de bens materiais, em razão disso, a sociedade passou a interferir de maneira mais intensa sobre os sistemas naturais, comprometendo o equilíbrio existente através da diminuição gradativa da capacidade de recuperação

natural dos recursos (MATAREZl et al., 2003).

Para isso, a Educação Ambiental (EA) possibilita a formação de valores e atitudes sensíveis à diversidade, à complexidade e à solidariedade diante dos outros seres humanos e da natureza (CARVALHO, 1998). Buscando uma recuperação harmônica, a qual supõe uma nova maneira de ver, de focalizar e viver nossas relações com o planeta Terra (GUTIERREZ \& PRADO, 2000).

Sendo favorecida uma EA trabalhada a partir das comunidades bioregionais, compreendendo assim, seu funcionamento e sua relação com o meio (BARBA \& SANZETENEA, 2002). Possibilitando para isso, quando na presença de áreas naturais, a realização de diversas ações educacionais ao ar livre (MENGHINI et al., 2007).

Atividades ao ar livre são práticas educacionais que utilizam como recursos os próprios desafios encontrados no ambiente, e que objetivam o desenvolvimento do ser humano (BARROS, 2000), através de novos valores, que alimentem as relações entre si e sua relação com a natureza, procurando sempre tomar novos rumos e buscar novos paradigmas (RUSCHEINSKY, 2001), fazendo-se crer, assim, na necessidade da reconstrução de novos elos por meio do vínculo emocional entre os seres humanos e o meio ambiente (MAYER, 1998).

Busca-se uma nova percepção ambiental, ou seja, um novo entendimento do indivíduo em relação ao meio ambiente incluindo os fatores sociais e culturais (WHITE, 1978).

Neste caso, o ambiente deve se inserir na perspectiva de aprendizado através de atividades interpretativas, proporcionando uma experiência direta entre o indivíduo e o meio ambiente, o que pode promover mudanças nessa relação (ROBOTTOM \& HART, 1993).

Dessa forma, as trilhas se encontram como mecanismos bastante difundidos para proporcionar o aprendizado da EA (TULLIO, 2005). A mesma EA que certamente pode ser um destes instrumentos 


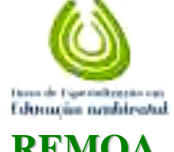

SANTOS \& PERES, vol.(4), $n^{\circ} 4$, p. 568-581, 2011. Monografias Ambientais (e-ISSN: 2236-1308)

REMOA

transformadores da sociedade, leva à construção da cultura da sustentabilidade, isto é, da convivência harmoniosa entre os seres humanos e a natureza (GADOTTI, 2000).

Quando nos referimos à EA, relacionamos o tema meio ambiente como foco central da educação. Entretanto, ela é mais que o ensino de ciências e de ecologia, pois tem como objetivo mudanças de atitudes (TOZONI-REIS, 2004). Uma teoria pedagógica que concebe a experiência como a base do aprendizado (BARROS, 2000).

Procurando para isso, desenvolver em cada indivíduo uma consciência que leve à compreensão dos processos e das inter-relações dos ambientes naturais e humanizados (ALEXANDRE \& DIOGO, 1990). O desenvolver desta consciência se dará através de experiências e desafios realmente vivenciados e não apenas verbalizados (CAPRA, 2003), fundamentados, principalmente, na mudança de mentalidade, comportamento e valores (REIGOTA, 2001).

Mas, apesar de fazer parte da filosofia das propostas curriculares atuais, ainda se esbarra na dificuldade dos professores em não se sentirem capacitados para implantarem, em suas programações letivas, projetos desta natureza (GRANDIS et al., 1999).

Assim, um dos meios mais utilizados é o dos percursos interpretativos, através de trilhas, onde, durante o percurso, o monitor interpreta o ambiente e estimula a participação do grupo alvo (PÁDUA \& TABANEZ, 1997).

As trilhas, enquanto instrumentos pedagógicos, devem explorar o raciocínio lógico, incentivando a capacidade de observação e reflexão, além de, apresentar conceitos ecológicos e estimular a prática investigatória (LEMES et al., 2004). Constituindo estratégias educativas adotadas para integrar o visitante à natureza, propiciando-lhe o conhecimento do ambiente e o possibilitando ser atuante na preservação das áreas silvestres (ROBIM \& TABANEZ, 1993).

Para Andrade e Rocha (1990) a principal função das trilhas sempre foi suprir a necessidade de deslocamento, no entanto, pode-se verificar que ao longo dos anos houve uma alteração de valores. Onde, de maneira geral, o destino final é normalmente o grande estímulo para que os visitantes iniciem uma trilha (REGNIER et al., 1992), mas é o percurso o responsável por conseguir promover um contato mais estreito entre o homem e a natureza (GUILLAUMON, 1977).

Então de simples meio de deslocamento, as trilhas surgem como novo meio de contato com a natureza (ANDRADE \& ROCHA, 1990).

Então, as TI mostram ser exemplos de atividades formativas e informativas, que provocam novos processos de adaptação e assimilação, relativos ao desenvolvimento de nossas experiências (DUBOS, 1974).

E que, quando bem planejadas, constituem importante instrumento pedagógico, o qual

propicia um contato mais próximo entre o homem e a natureza (CARVALHO \& BOÇÓN, 2004), trazendo novos valores que contribuem para um envolvimento na conservação do meio ambiente e no exercício pleno da cidadania (PÁDUA et al., 2004). Cabe ao guia, despertar essa curiosidade do visitante sobre o ambiente, preocupando-se ainda, em sempre aumentar a qualidade da experiência durante visita (MAGRO \& FREIXÊDAS 1998).

Ao percorrer uma $\mathrm{TI}$, descobre-se as relações de coincidências e de complementaridades solidárias entre si e com outros grupos humanos (GUIMARÃES, 2007). Estas experiências propiciam várias leituras de uma mesma realidade ambiental, considerando a análise e a interpretação das diversas dimensões paisagísticas (LIMA, 1998).

Portanto, as trilhas visam, não somente a transmissão de conhecimentos, mas também propiciam atividades que revelam os significados e as características do ambiente por meio do uso dos elementos originais (PÁDUA \& TABANEZ, 1997). Isso possibilita a re-significação de contextos e conteúdos e transformações do significado de experiências ambientais anteriores, alterando reações, 
REMOA

atitudes e condutas referentes à valorização do meio ambiente (LIMA, 1998). É possível, dessa forma, entender a TI como um diálogo, sobre o apreender do dinamismo do mundo vivido (BUTTIMER, 1985/a).

Um processo de socialização que leva ao reencontro das sensibilidades da natureza e à identificação do sentido de pertinência em relação ao próprio grupo de trabalhos, de forma cooperativa e integradora (BATESON, 1985; GUATTARI, 2001; MORAIS, 1993).

É preciso estar consciente das mudanças que devem ser promovidas pelo homem em sua maneira de encarar o próprio planeta, tanto as de iniciativa governamental quanto as individuais (MARCONDES \& SOARES, 1991).

É através da educação que, entendida como educação para a vida, é que o ser humano pode desenvolver um amor por si mesmo, pelo outro e pelo ambiente em que se encontra (PÁDUA, 1997). Encontra-se assim, condições de mudar aquilo que de fato pode ser mudado entre a experiência e a esperança, considera-se para isso toda a importância da EA (MORAIS, 1993). Uma educação sobre aprendizados significativos e vivenciais, ou seja, uma educação sobre valores para se viver (BARYLKO, 1999; WAISMAN \& SHOCRON, 2001).

Vê-se a EA, como, talvez, a melhor porta de entrada para um pensamento tão amplo, uma vez que questiona os valores dos modelos vigentes, propondo relacionamentos mais harmônicos entre todos os seres vivos do planeta (PÁDUA, 1997).

A TI, por sua vez, deve ajudar o visitante a desenvolver o sentimento de "estar em casa" quando em contato com a natureza (SHARP, 1976), possibilitando uma grande diversidade de eixos temáticos e abordagens ecológicas tanto com finalidades educativas, como em atividades de pesquisa e investigação científica (VASCONCELOS et al., 2009).

Estudos sobre a utilização de trilhas interpretativas no município de Cruz Alta e região são escassos, dessa forma, a implantação de uma trilha ecológica como instrumento pedagógico interpretativo, pode ser responsável por desenvolver no educando uma participação responsável e eficaz, na concepção e aplicação das decisões sobre a qualidade do meio natural, e da transformação do ser humano em agente multiplicador da melhoria da qualidade de vida, com o desenvolvimento individual e coletivo de atitudes éticas, isso sem mencionarmos a aquisição de valores em relação à natureza, através de uma dinâmica de observação, de interação, de reflexão e de sensibilização, proporcionando a possibilidade da "adoção" de um novo comportamento, mais justo e sustentável.

\section{MATERIAL E MÉTODOS}

Visando a construção de um ensaio teórico consistente o projeto fez uso de reflexões obtidas através do método dedutivo, adotando-se para a atividade de campo a metodologia de resgate/análise critica, com a aplicação de trilhas guiadas e de interpretação da natureza ("Nature Trails").

Como sujeito da pesquisa, teve-se alunos do ensino médio da Escola Estadual de Ensino Médio Major Belarmino Côrtes, de Cruz Alta/RS. Contemplando cinco turmas, dois 1ㅇaㅇ anos dois 20 anos e um 30 ano, com 100 alunos totalizados.

A área empregada situa-se no Estado do Rio Grande do sul, estando localizada sob as coordenadas 2837'45.2" S e 5338'31.4" O e pertencendo a Estância Lara Gruhn, compreendendo oito hectares do município de Cruz Alta, com entrada pela direção noroeste da região urbana do município, a qual, lindeira ao Bairro Santa Tereza II. 


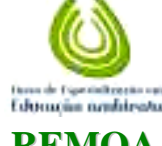

SANTOS \& PERES, vol.(4), $n^{\circ} 4$, p. 568-581, 2011. Monografias Ambientais (e-ISSN: 2236-1308)

REMOA

Situada na região do Planalto Médio, a uma altitude entre 400 e 500 m, com relevo predominantemente ondulado.

O clima segundo classificação de Koppen é o subtropical, com verões quentes, pluviosidade no mês mais seco entre 30 e $60 \mathrm{~mm}$, precipitação média anual de $1.729 \mathrm{~mm}$, com temperaturas médias de $22 \circ \mathrm{C}$ e superiores no mês mais quente e 18 ㅇ C e inferiores no mês mais frio, a média anual é de 18,4으 (MALUF, 2000).

A área de estudo constitui um fragmento de Floresta Estacional Semidecidual, com uma formação florestal representada por um fragmento de diferentes estruturas vegetais, circundados por lavouras de monocultura e pastagem.

Consistindo simplificadamente em uma trilha de curta distância com 1.600 metros, tendo uma duração aproximada de 120 minutos, incluso um intervalo de 30 minutos e apresentando um caráter educativo com programação desenvolvida a partir da interpretação do ambiente natural, com um percurso (forma) em oito, o qual, muito eficiente em áreas limitadas, pois comumente aumenta a possibilidade de "exploração" destes espaços, sendo considerada fácil, quanto ao seu grau de dificuldade.

Este trajeto foi escolhido e definido, a partir de trechos já abertos pelo próprio proprietário, evitando assim, a conseqüente eliminação desnecessária da vegetação existente para a abertura de um novo trajeto, tendo em vista ainda, as possíveis dificuldades quanto à acessibilidade da mesma.

Foram analisados os elementos relevantes apontados durante o estudo da área, e desta forma, foi elaborado um roteiro interpretativo com enfoque na interpretação temática e da percepção ambiental.

Sendo marcados oito pontos ao longo da trilha, escolhidos segundo critérios de acessibilidade, visualização dos elementos naturais presentes e principalmente a possibilidade de interação com a mesma, colocando o ser humano como parte integrante, fundamental e responsável pelo meio ambiente.

Onde se pode observar as expectativas dos participantes antes da realização da trilha, dos fatos que receberam destaque durante e principalmente sua posição ao término. A avaliação foi processual, sendo utilizados instrumentos e técnicas de avaliação instantânea e questionários. Com essa ação interativa entre homem e natureza, colocou-se em prática um pouco da tão almejada política nacional de Educação Ambiental.

Os resultados foram avaliados em razão do desenvolvimento de uma compreensão versátil do entorno, onde se pode identificar os estímulos e apreciação refletidos em uma nova visão e um novo pensamento sobre as realidades ambientais experienciadas, e as circundantes ou não. Para melhor compreensão dos dados, foram montados gráficos elaborados através do programa Excel (WINDOWS, 2007).

\section{RESULTADOS E DISCUSSÃO}

Dentro das perspectivas da Educação Ambiental (EA) foram desenvolvidas Trilhas Interpretativas (TI), através de práticas ao ar livre, desencadeando ações viáveis e ambientalmente corretas, através de um "despertar" de uma consciência sócio ambiental mais equilibrada e sustentável, além da construção de uma cidadania solidária e globalizada.

Sendo desenvolvidas e aplicadas em três dias consecutivos (27, 28 e 29 de junho de 2011), correspondendo respectivamente um dia para cada ano do ensino médio, objetivando assim, uma me- 


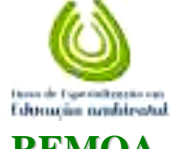

SANTOS \& PERES, vol.(4), $n^{\circ} 4$, p. 568-581, 2011. Monografias Ambientais $\quad$ (e-ISSN: 2236-1308)

REMOA

Ihor maneira de desenvolver as atividades, respeitando para isso, a capacidade de suporte da triIha, e também, o correto manejo das atividades propostas, mostraram-se assim, com um baixo nível de dificuldade, podendo ser percorrida por visitantes de qualquer idade.

Fundamentado não somente nos resultados obtidos através dos questionários, mas também, na manifestação individual e coletiva dos participantes, foi possível perceber uma variação gradativa na faixa etária, que foi desde os quatorzes aos dezenove anos (Figura 1). O que demonstrou uma presença significativa de alunos repetentes, e inclusive, de alunos que por algum motivo deixaram a escola (evasão) em um dado momento e "agora" estavam a retornar. Onde o importante a se ressaltar, é que esses alunos aceitaram de forma positiva a atividade, participando e interagindo efetivamente a todo o momento, até mesmo, mais do que os outros. O que segundo Troncin (2005) não é comum, já que normalmente os repetentes oferecem sistematicamente sinais negativos a essas situações, ou seja, rejeição durante a participação em atividades que exigem certa socialização ou participação em grupo. Tanto a evasão, quanto a repetência são sérios problemas, verdadeiras patologias instaladas nas mais variadas modalidades de ensino da escola, e esse é o lugar sobre o qual se deve, prioritariamente interferir, com a criação de alternativas na forma de ensino (FERNANDES, 2001). E quando se fala em alternativas, fala-se não somente em trilhas, mas também a todas aquelas propostas que fogem ao ambiente tradicional de sala de aula e que oferecem uma contextualização mais prática e direta dos temas a serem abordados.

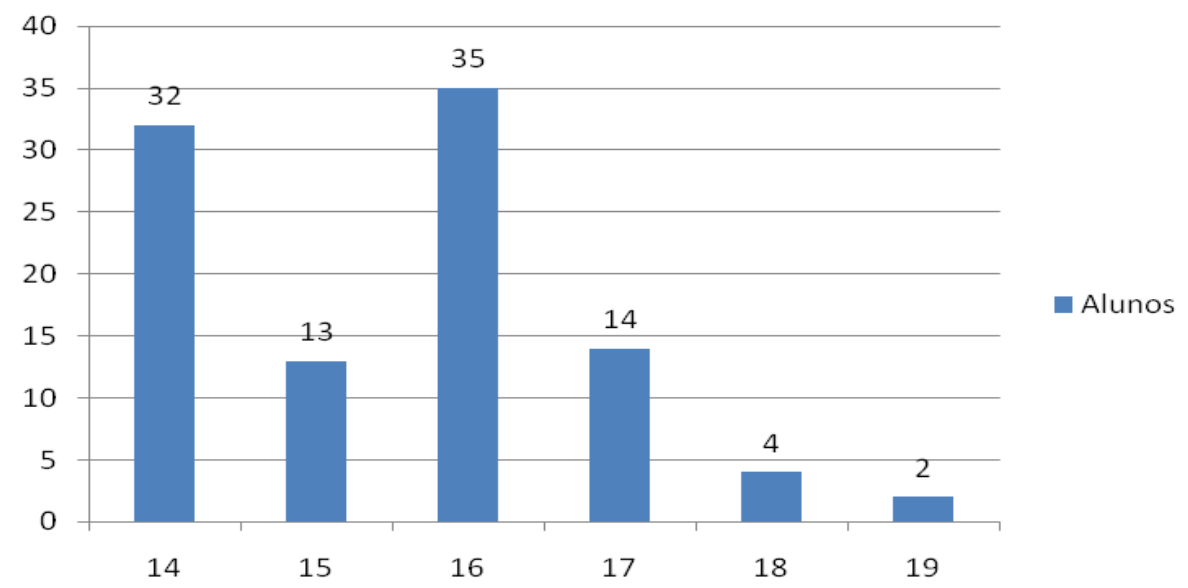

Figura 1 - Variação da faixa etária (em anos) proporcionais ao número de alunos.

Utilizando o gráfico abaixo (Figura 2), pode-se perceber facilmente a diferença de participantes quanto ao gênero, com 66 meninas e 34 meninos, o que é comum de certa forma na maioria das escolas. Já que há uma socialização diferenciada de meninos e meninas, onde as meninas normalmente se sobressaem mais, o que diminui a sua evasão, mas não significando necessariamente que as elas aprendem mais do que os meninos (CARVALHO, 2003). Esse contraste entre os sexos acentua-se gradativamente com o passar dos anos, ou seja, quanto mais alto for o "grau" de escolaridade atingido, maior o número de meninas em relação à de meninos. É preciso rever metodologias e buscar meios para se equilibrar essa desigualdade, partindo inicialmente da compreensão de todos os mecanismos envolvidos nesse fenômeno. 


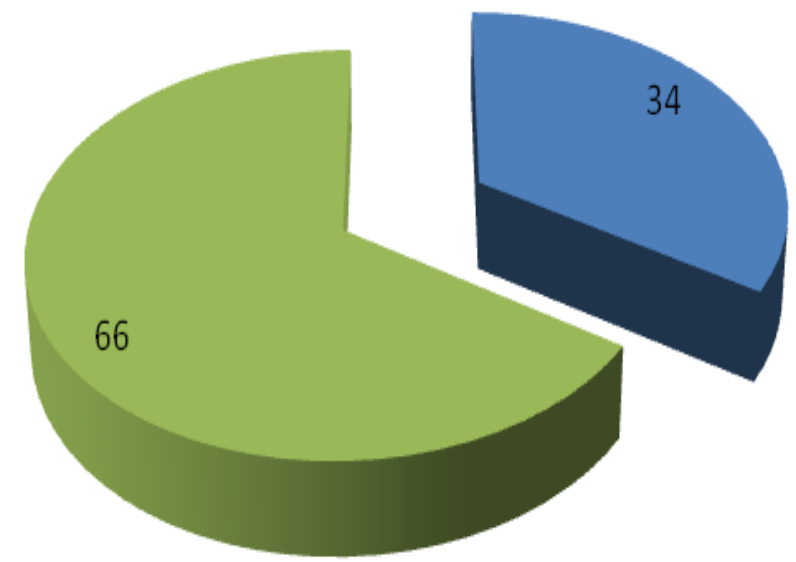

Masculinos

Femininos

Figura 2 - Variação quanto ao gênero, proporcionais ao número de alunos.

Mesmo com a proliferação cada vez maior da utilização de TI, como mecanismos de conscientização ambiental, apenas $16 \%$ dos entrevistados afirmam já terem participado de alguma trilha antes, a qual, segundo relatos, realizada durante uma determinada excursão em sua escola, mas como dito por eles mesmos, sem nenhum cunho educativo, apenas turístico. Assim, a maioria esmagadora com $84 \%$ dos alunos, relatam não terem participado, sequer, de nenhuma atividade ao ar livre que se assemelha ao menos com uma trilha, ou ao menos, que possibilita-se o confronto da teoria com a prática.

O uso de trilhas para a interpretação de áreas naturais tem sido freqüentemente recomendado por oferecer oportunidades de contato direto com o ambiente natural, direcionando ao aprendizado e à sensibilização, além do comprometimento com as causas ambientais.

Tentando resolver situações como essa, Vasconcellos (2003) recomenda a implantação de TI de uso público, já que estas são consideradas importantes meios educativos e recreativos, independentes do método que se utilizam.

Através da interpretação ampliamos os horizontes dos estudos, diante das várias maneiras de experienciarmos o meio ambiente e nos reintegrarmos a ele, destacando-se para isso os processos imagéticos criativos e envolventes (GUIMARÃES, 2004; 2007).

Nesse sentido, a interpretação em áreas naturais é uma estratégia educativa que integra o ser humano com a natureza, motivando-o a contribuir para a preservação da mesma (ROBIM \& TABANEZ, 1993).

Dando prosseguimento, percebe-se que 92\% já ouviram falar em Educação Ambiental (EA), seja em sala de aula ou em programas de televisão, ou ainda, por outros meios, como a internet e o rádio. Enquanto os demais $8 \%$, disseram não saber se quer do que se tratava ou que nunca tinham ouvido falar antes, algo no mínimo curioso para alunos do ensino médio e que se dizem atentos a todos os acontecimentos do mundo.

Porcentagem essa quase que inexpressiva é verdade, porém preocupante, uma vez que a EA tem como papel fundamental a formação das consciências individuais e coletivas, uma consciência que, se sensibilizada com os problemas sócio-ambientais (WEID, 1997).

Onde, Burnham (1993) considera ainda, a educação como um processo social indispensável à formação da mentalidade dos cidadãos, através de um processo de transformação e desenvolvimento da sociedade. Machado (1982) afirma então, que só cuidamos, respeitamos e preservamos aquilo que conhecemos e que a ignorância traz uma visão distorcida da realidade, onde os problemas ambientais são causados pela uma falta de "conhecimentos" e que a solução reside, portanto, na informação. Como bem salienta Segura (2001), o conhecimento é essencial tanto para embasar 


\section{REMOA}

uma leitura crítica da realidade, quanto para buscar instrumentos para solucionar problemas ambientais mais concretos.

O ensino pautado somente nas idéias, no abstrato e, sobretudo, na fragmentação do conhecimento tem contribuído para um desânimo, uma indiferença e um desprezo em relação ao conhecimento. Enfatizando assim, a necessidade de uma EA que busca desenvolver um conhecimento para adquirir valores, mentalidade e atitudes necessárias para lidar com as questões e problemas ambientais, encontrando sempre soluções sustentáveis (DIAS, 2003).

Fazendo ainda, uso dos recursos gráficos (Figura 3), é possível ver mais especificadamente como a EA é trabalhada em sala de aula na referida instituição de ensino, segundo depoimento dos próprios alunos.

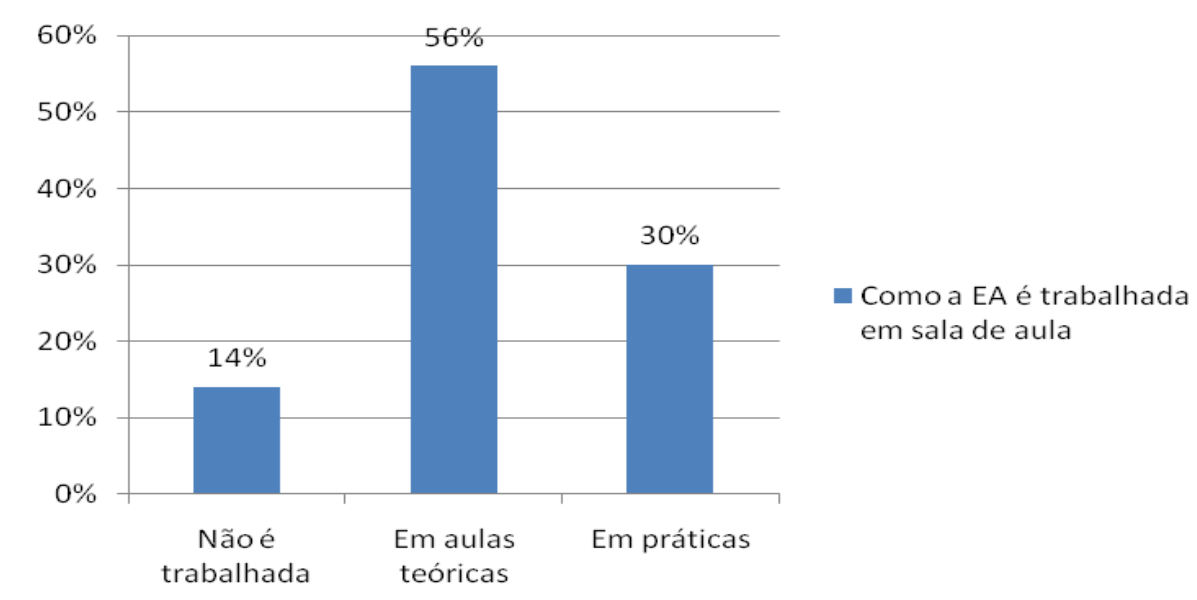

Figura 3 - Forma de abordagem da Educação Ambiental em aula.

Onde, 14\% disseram que ela não é trabalhada de nenhuma forma, porém, 30\% confessaram já terem participado de uma ou outra aula prática durante todo o ensino médio, mas a maioria (56\%) afirmou que a escola possibilitou poucos momentos para a realização de atividades práticas, mesmo que possuindo laboratórios de química/biologia, de informática e uma sala de vídeo, afirmando ainda, que esses não são freqüentemente utilizados, o que demonstra de forma clara, a falta de motivação por parte dos professores, o que pode ter sido influenciado talvez, pela falta de um pátio amplo ou área verde próxima para a realização de atividades ao ar livre, assim como, pela falta de preparo para a utilização dos laboratórios. Muitas vezes, os professores não exploram adequadamente as oportunidades oferecidas, por simples desconhecimento sobre o local a ser usado, o que acarreta em insegurança e despreparo quanto à maneira de lidar com as situações que podem vir a surgir (BENETTI, 2002).

Portanto alunos e professores, muitas vezes, apontam a sala de aula como um ambiente entediante, sem muitos atrativos (CARVALHO, 1989; CHAPANI \& CAVASSAN, 1997; BENETTI, 2002). O professor deve conhecer o mundo e ser capaz de instruir os outros acerca deste. As referências positivas, no contexto de uma aula tradicional, podem ser advindas de um ensino reflexivo, da ideologia implícita ou explícita na ação docente. Todavia, o contexto de uma aula de campo, pode favorecer o estabelecimento de referências positivas. Concordando assim, com Dias (2003) que a EA deve prover os meios de percepção e compreensão dos vários fatores que interagem no tempo e 


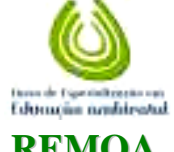

SANTOS \& PERES, vol.(4), nº, p. 568-581, 2011. Monografias Ambientais $\quad(e-I S S N$ : 2236-1308)

REMOA

no espaço para modelar o meio ambiente, deve ajudar os indivíduos a sensibilizarem-se, a adquirirem consciência.

Os questionário e depoimentos evidenciam que poucos professores costumam discutir os valores ambientais durante as suas aulas (Figura 4), ocorrendo usualmente nas disciplinas de ciências biológicas, geografia e história apenas. O que pode denunciar a falta de uma transdiciplinaridade no currículo escolar, assim como, um programa político pedagógico apenas utópico, por não efetivar movimentos reflexivos e investigativos, capazes de impulsionar a ultrapassagem das fronteiras das disciplinas e de ousar transitar livremente por elas, independentemente do tema.

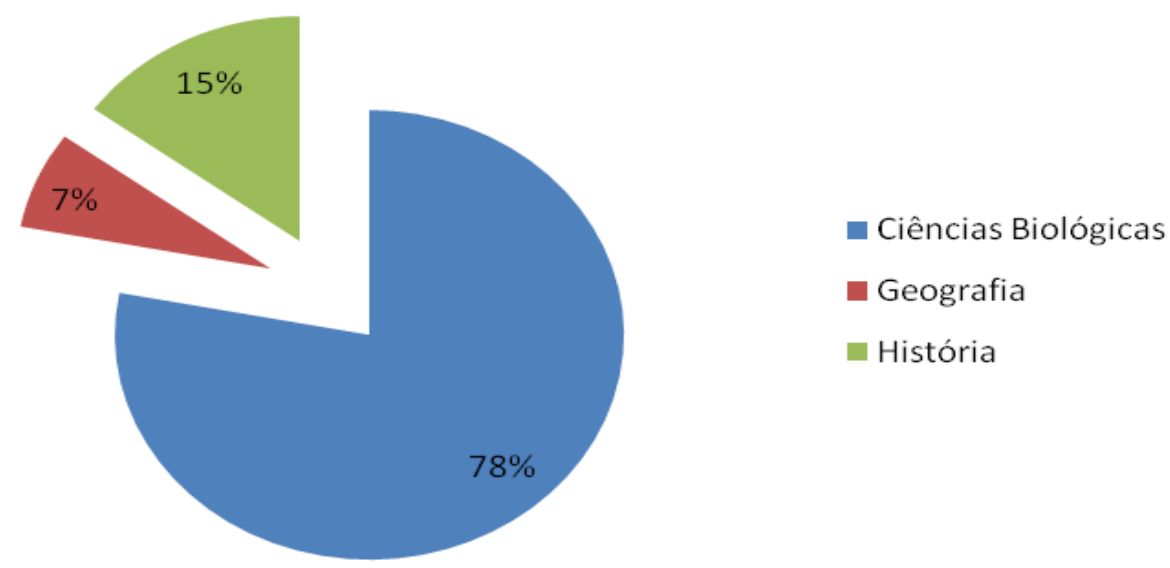

Figura 4 - Discussão dos valores ambientas de acordo com as disciplinas.

Levando em consideração apenas o seu ponto de vista, 92\% dos participantes acreditaram que a trilha realizada, contribuiu certamente, de alguma forma para a formação de uma consciência socioambiental mais equilibrada, o que os levou a refletir e a questionar-se sobre atitudes do seu dia-a-dia, chegando até mesmo a discutirem e inclusive sugerirem soluções para alguns dos problemas.

A EA, portanto, pode contribuir sim, para um processo de transformação da sociedade atual em uma sociedade sustentável, centrada no exercício responsável da cidadania (SADER, 1992). Ocasionando a sensibilização dos sujeitos, com o objetivo de indicar subsídios para garantir a sustentabilidade do meio em que vivem.

Conforme Reigota (1998) a EA não visa exclusivamente à utilização racional dos recursos naturais, mas, além disso, necessita da participação dos cidadãos nas discussões e decisões sobre a questão ambiental.

Os $8 \%$ restantes afirmaram que atividades como essa, só servem como atividade física, pois sem uma "aula formal" com livros e um quadro negro não são capazes de assimilar e nem discutir quaisquer que sejam os assuntos. Nesse caso eles não se identificaram com a natureza e as emoções desencadeadas não foram positivas então.

Um posicionamento desta natureza, contudo, não deve desestimular o desenvolvimento das aulas em ambientes naturais, mas antes representar um desafio, que auxilie o aluno a construir novos valores para o entendimento da natureza e de si mesmo. Machado (1982) nos alerta que as crianças urbanas apresentam, muitas vezes, idéias distorcidas sobre o meio natural, e assim, mostramse frustradas ao confrontar essa realidade.

Conforme Paulo Freire (2004), enquanto não houver diálogo entre os sujeitos sobre as ações, políticas e estratégias de educação e formação, aqui no caso para a EA, poucos impactos consideráveis positivos serão atingidos. 


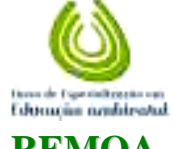

SANTOS \& PERES, vol.(4), nº, p. 568-581, 2011. Monografias Ambientais (e-ISSN: 2236-1308)

REMOA

Os mesmos $92 \%$ mencionados anteriormente, demonstraram que os conhecimentos adquiridos durante a trilha podem sim, ser utilizados no seu dia-dia, bastando para isso usar um pouco do bom senso e de criatividade, mas principalmente, adequando as respostas de acordo com os problemas, fazendo-se para isso, valer-se apenas dos princípios básicos discutidos e assimilados durante a atividade de interpretação ambiental.

Porem o restante (8\%), infelizmente não acredita nessa possibilidade, o que leva a discutirmos a possibilidade de alterações durante percurso e também no método de abordagem da trilha, com o intuito de tentar cativar esses alunos. Porém, Dias (2003) cita que uma das falhas mais comuns ao sucesso de projetos de EA se dá por conta da falta de envolvimento das pessoas em determinadas ações, onde muito mais do que a informação, a sensibilidade deve ser adquirida.

Uma observação atenta e criteriosa, isso para não dizer curiosa mesmo, durante todo o percurso da trilha, proporcionou uma visualização prática, da aproximação afetiva ocorrida entre os visitantes e o meio ambiente, fato esse manifestado por quase todos. Afinal de contas "o ser humano é movido por emoções, caso elas não sejam estimuladas, a resposta não ocorre" (DIAS, 2003, p. 126).

Os alunos puderam ainda, manifestar após o término da trilha, quais foram os elementos que mais Ihes chamaram a atenção durante o percurso, o que pode ser mais bem demonstrado pelo gráfico abaixo (Figura 5).

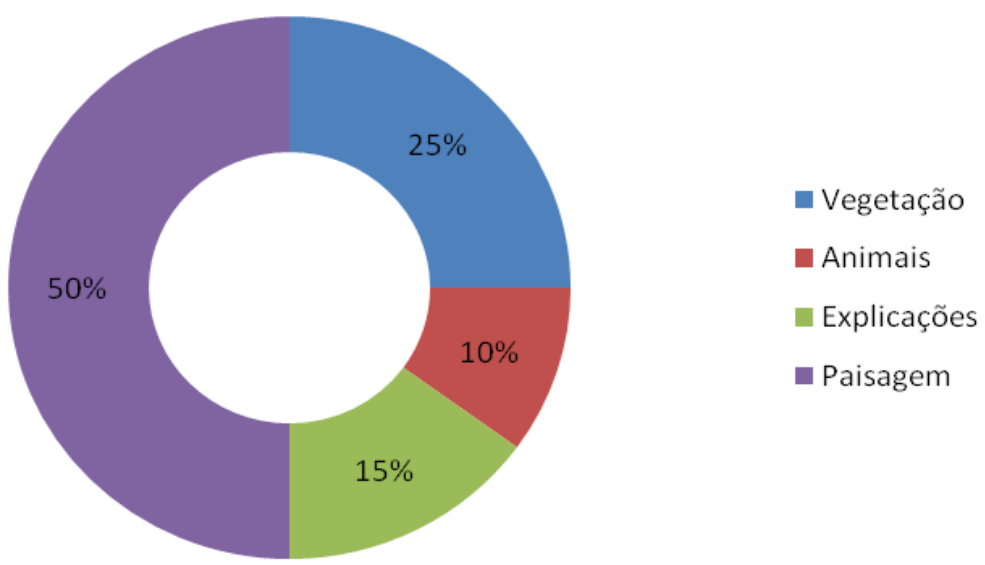

Figura 5 - Elementos que mais chamaram a atenção durante o percurso.

Ressalte-se, nesses resultados, que os alunos aceitaram de modo natural as diferenças e características que observaram isso porque, lhes foi dada a oportunidade de julgarem por si mesmos sobre seu aspecto.

Percebe-se então, que metade da atenção foi gerada pela contemplação da paisagem como um todo, uma visão holística e que a sua desconstrução em partes, como na vegetação (25\%) e animais (10\%) tiveram menos expressão, assim como, as explicações (15\%) dadas durante os "Pontos de parada", o que salienta ainda mais a eficácia da utilização desse tipo de atividades, mesmo que sem a orientação de um guia.

A partir desses resultados, podemos inferir que os objetivos alcançados pelos alunos não poderiam surgir no contexto de uma aula tradicional.

Os entrevistados foram questionados sobre as impressões que tiveram com a visita às trilhas, e de acordo com as respostas obtidas, pode-se perceber que para a maioria, as impressões positivas superaram as negativas. 


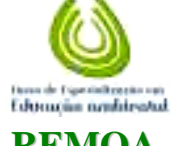

SANTOS \& PERES, vol.(4), $n^{\circ} 4$, p. 568-581, 2011. Monografias Ambientais (e-ISSN: 2236-1308)

REMOA

Eles afirmaram, que sentiram-se a vontade durante todo o percurso e que o ambiente a sua volta apresentou grande diversidade de espécies, e que os assuntos abordados foram explanados de forma clara e objetiva, e principalmente, completamente inter-relacionadas com a natureza e sua relação com o homem.

Puderam presenciar tanto espécimes vegetais, como gramíneas, herbáceas, vassourais, pequenas e médias arvoretas, além de grandes árvores, isso sem contar, ecossistemas diferenciados, assim como, uma diversidade de aves, de entomofauna, de anfíbios e lacertílios muito grande, uma significativa amostra da flora e fauna da região a qual pertencem.

Percebendo então, que "quando se tem o conhecimento", vemos o meio ambiente com outros olhos, o que antes passaria despercebido ou não teria importância alguma, passa a ser "um tema gerador" de longas conversas e discussões, possibilitando o confrontamento da teoria com a prática, por meio da experimentação de vivências e interpretação do meio.

Há práticas simples de EA que podem ser aplicadas facilmente e que não necessitam de altos investimentos, mas sim de consciência e quebras de paradigmas, no sentido de assimilar novos hábitos culturais para a sustentabilidade. Onde, a educação e percepção para as questões ambientais despontam como armas na defesa do meio natural, e contribuem na reaproximação do homem com a natureza.

\section{CONCLUSÃO}

A partir da experimentação das situações vivenciadas e da análise das respostas obtidas nos questionários, assim como, através de suas opiniões durante todo o processo de Interpretação Ambiental (IA), se observou que existe um certo distanciamento entre os conhecimentos já adquiridos em sala de aula, daqueles contextualizados em sua vida cotidiana, assim, acredita-se que esse estudo contribuiu tanto para o enriquecimento da pesquisa científica relacionada ao desenvolvimento de novas ações metodológicas para as práticas de Educação Ambiental (EA), bem como, aproximar a teoria da prática, tornando possível o conhecimento, por exemplo, de parte da flora e fauna local, e também, da reflexão das questões ambientais das quais fazem parte, desde suas casas até o mundo que os cerca. Assim a IA cumpre aliada à EA, papel fundamental no processo de informar, e principalmente, sensibilizar as pessoas para a compreensão da complexa temática ambiental, aonde, IA é uma busca de significados e não apenas a informação. Ao realizar-se uma trilha interpretativa e guiada, através de um método interativo e participativo, foi possível colocar os alunos em contato direto com a natureza e propiciar uma nova percepção ambiental, compreendendo assim, um pouco das intrincadas relações entre o ser humano e o meio ambiente, e a partir desse conhecimento começou-se uma nova integração socioambiental, motivadas pela conscientização e pela mudança de hábitos, fazendo-os refletir e a questionar-se sobre suas atitudes e principalmente sobre o seu modo de vida, passando então, a agirem de forma mais sustentável, tanto individualmente como coletivamente, promovendo ainda, a sua transformação em agentes multiplicadores de valores ambientais e sociais, os quais, essencialmente necessários para a perpetuação de um mundo mais ético e ecologicamente sustentável e porque não, mais humano.

\section{REFERÊNCIAS}

ALEXANDRE, F.; DIOGO, J. Didática da Geografia - Contributos para uma educação no ambiente, Lisboa, Texto Editora, 1990. (Coleção “Educação Hoje”). 
ANDRADE, W.J.; ROCHA, L.M. Planejamento, implantação e manutenção de trilhas. In: Congresso Florestal Brasileiro, 6ạ ed., Campos do Jordão, 1990. Anais - São Paulo, SBS/SBEF, 1990, v.3, p.86-93.

BARBA, A.T.; SANZETENEA, J.P. La educación ambiental y la comunidad educativa. In: SAUVÉ, L.; ORELLANA, I. \& SATO, M. Textos escolhidos em Educação Ambiental - de uma América à outra. Québec: Lês Publications ERE-UQAN, 2002, Tomo I, p.101-105.

BARROS, M.I.A. Outdoor Education: uma alternativa para a educação ambiental através do turismo de aventura. In: SERRANO, Célia (Org.). A Educação pelas Pedras. São Paulo: Chronos, 2000, p.85-110.

BARYLKO, J. Educación en Valores. Buenos Aires: Ameghino, 1999.

BATESON, G. Pasos hacia una ecología de la mente. Buenos Aires: Ediciones Carlos Lohlé, 1985.

BENETTI, B. A temática ambiental e os procedimentos didáticos: perspectivas de professores de Ciências. In: VIII ENCONTRO PERSPECTIVAS DO ENSINO DE BIOLOGIA, 6ạed., 2002, São Paulo. Anais... São Paulo: FEUSP, 2002. (1 CDROM).

BERNA, V. Como fazer Educação Ambiental. São Paulo: Paulus, 2001.

BURNHAM, T.F. Educação ambiental e reconstrução do currículo escolar. Caderno Cedes Educação Ambiental, Campinas, v.29, n.1, 1993, p.21-30.

BUTTIMER, A. Apreendendo o Dinamismo do Mundo Vivido. In: CHRISTOFOLETTI \& ANTONIO, Perspectivas da Geografia. São Paulo: DIFEL, 1985/a, p.165-193.

CAPRA, F. Alfabetização Ecológica: desafio para a educação do século 21. In: TRIGUEIRO,

A. (Org.). Meio Ambiente no século 21. Rio de Janeiro: Sextante, 2003.

CARVALHO, J.; BOÇÓN, R. Planejamento do traçado de uma trilha através da caracteriza ção florística. Revista Floresta, v.34, 2004, p.23-32.

CARVALHO, M.P. Sucesso e fracasso escolar: uma questão. Educação e Pesquisa, v.29, n.1, São Paulo, 2003, p.185193.

CARVALHO, L.M. A temática ambiental e a escola do 10 grau. São Paulo, 1989. 286f. Faculdade de Educação, Universidade de São Paulo. (Tese de Doutorado em Educação).

CHAPANI, D.T.; CAVASSAN, O. O estudo do meio como estratégia para o ensino de Ciências e educação ambiental. Mimesis, Bauru, v.18, n.1, 1997, p.19-39.

DIAS, R. Turismo sustentável e meio ambiente. São Paulo: Atlas, 2003.

DUBOS, R. Um Animal Tão Humano. São Paulo: Melhoramentos/EDUSP, 1974.

FERNANDES, A. Os idiomas do aprendente: analise de modalidades ensinantes em famílias, escolas e meios de comunicação. Porto Alegre: Artmed Editora, 2001.

FREIRE, P. Pedagogia da autonomia: saberes necessários à prática educativa. 30ạ edição. São Paulo: Paz e Terra, 2004.

GADOTTI, M. Perspectivas atuais da educação. Porto Alegre: Artes Médicas Sul, 2000.

GRANDIS, C.A.M. et al. Curso de Educação Ambiental na Estação Ecológica dos Caetetus para professores de 1 e 20 graus. Assis: Floresta Estadual de Assis, 1999. (Relatório Anual da Floresta Estadual de Assis). 


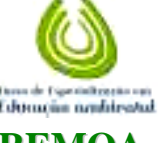

SANTOS \& PERES, vol.(4), n4, p. 568-581, 2011. Monografias Ambientais $\quad(e-I S S N$ : 2236-1308)

REMOA

GUIMARÃES, S.T.L. Paisagens: aprendizados mediante experiências. Um ensaio sobre interpretação e valoração da paisagem. Rio Claro/SP: Universidade Estadual Paulista - Instituto de Geociências e Ciências Exatas, 2007. (Tese LivreDocência).

. Dimensões da Percepção e Interpretação do Meio Ambiente: vislumbres e sensibilidades das vivências na natureza. OLAM - Ciência \& Tecnologia, v.4, n.1, 2004, p.46-64.

GUATTARI, F. As Três Ecologias. 11a ed. Campinas: Papirus, 2001, 56p.

GUILLAUMON, J.R.; POLL, E.; SINGY, J.M. Análise das trilhas de interpretação. São Paulo: Instituto Florestal, 1997, 57p. (Boletim Técnico).

GUIMARÃES, S.T.L. Paisagens: aprendizados mediante experiências. Um ensaio sobre interpretação e valoração da paisagem. Rio Claro/SP: Universidade Estadual Paulista - Instituto de Geociências e Ciências Exatas, 2007. (Tese LivreDocência).

GUTIERREZ, F.; PRADO, C. Ecopedagogia e cidadania planetária. 2ª ed. São Paulo: Cortez: Instituto Paulo Freire, 2000.

LEMES, E.O.A. et al. Criação de 3 trilhas interpretativas como estratégia em um programa de interpretação ambiental do Parque Estadual do Itacolomi. Relatório do Projeto:

UFOP: Ouro Preto, 2004.

LIMA, S.T. Trilhas Interpretativas: a aventura de conhecer a paisagem. Cadernos Paisagem,

Rio Claro: UNESP, v.3, n.3, 1998/maio, p.39-44.

MACHADO, A.B.M. Conservação da natureza e educação. In: Congresso Nacional sobre Essências Nativas, 1982, Campos do Jordão. Anais... Campos do Jordão: [s.n.], 1982, p.109-108.

MAGRO, T.C.; FREIXÊDAS, V.M. Trilhas: como facilitar a seleção de pontos interpretativos. Circular Técnica IPEF. n.186, 1998, p.4 -10.

MALUF, J.R.T. Nova classificação climática do Estado do Rio Grande do Sul. Revista Brasileira de Agronomia, Santa Maria, v.8, n.1, 2000, p.141-150.

MARCONDES, A.C.; SOARES, P.A.T. Curso Básico de Educação Ambiental. São Paulo:

Scipione, 1991.

MAYER, M. Educación ambiental: de la acción a la investigación. Enseñanza de las Ciencias, Barcelona, v.2, n.16, 1998, p.217-231.

MATAREZI, J. et al. Educação ambiental em unidades de conservação. Documento de mini curso realizado no 20 Simpósio Brasileiro de Engenharia Ambiental, Itajaí, 5-8 outubro de 2003. (CD-ROM).

MENGHINI F.B; MOYA-NETO, J; GUERRA A.F.S. Interpretação ambiental. In: Ferraro- Junior, L.A (Org). Encontros e caminhos: formação de educadoras (es) ambientais e coletivos educadores. MMA (Ministério do Meio Ambiente), Diretoria de Educação Ambiental, Brasília, v.2, 2007, p.209-218.

MORAES, M.C. Contextualizando a problemática educacional. In: Délcia Enricone e Marlene Grillo. (Org.). Educação Superior: vivências e visão de futuro. 1a ed. Porto Alegre: EDIPUCRS, p.25-46, 2005.

MORAIS, R. Ecologia da mente. Campinas: Editorial Psy, 1993.

PADUA, S.M.; TABANEZ, M.F. Uma abordagem participativa para a conservação de áreas naturais: Educação ambiental na mata atlântica. Anais do Congresso brasileiro de comunidades de conservação. Curitiba - Paraná, v.2, 1997. 
PÁDUA, S.M.; TABANEZ, M.F.; SOUZA, M. A abordagem participativa na educação para a conservação da natureza. In: CULLEN JR., L.; RUDRAN, R.; VALLADARESPADUA, C. Métodos de estudo em Biologia da Conservação e manejo da vida silvestre. Curitiba: Ed. da UFRP/Fundação O Boticário de Proteção à Natureza, 2004, p.557-569.

REGNIER, K.; GROSS, M.; ZIMMERMAN, R. The interpreter's guidebook: techiniques for programs and presentations. Stevens Point: VW-SP Foundation, 1992, 101p.

REIGOTA, M. O que é educação ambiental? 3ạ ed. São Paulo: Brasiliense, 2001.

REIGOTA, M. Meio ambiente e representação social. São Paulo: Cortez, 1998.

ROBIM, M.J.; TABANEZ M.F. Subsídios para implantação da Trilha Interpretativa da Cachoeira - Parque Estadual de Campos do Jordão - SP. Revista do Instituto Florestal, São Paulo, v.5, n.1, 1993, p.65-89.

ROBOTTOM, I.; HART, P. Research in environmental education: engaging the debate.Univerity and Griffith University. Deakin University Press: Victoria, 1993.

RUSCHEINSKY, A. Meio ambiente e percepção do real: os rumos da educação ambiental nas veias das ciências sociais. Revista Eletrônica do Mestrado em Educação Ambiental. Rio Grande, v.7, [s.p.], out/nov/dez. 2001.

SADER, E. A ecologia será política ou não será. In: GOLDENBERG, M. (Org.) Ecologia, ciência e política: participação social, interesses em jogo e luta de idéias no movimento ecológico. Rio de Janeiro: Revan, 1992, p.135-42.

SEGURA, D.S.B. Educação Ambiental na Escola Pública. São Paulo: FAPESP/ANNABLUME, 2001.

SHARP; GRANT, W. Interpreting the Environment. USA, [s.I.], [s.v.], [s.n], 1976.

TRONCIN, T. Le Redoublement: radiographie d'une décision à la recherche de sa légitimité. Djon, Thèse (doct.). Université de Dijon, 2005.

TÚLLIO, A.D. A abordagem participativa na construção de uma Trilha Interpretativa como estratégia de Educação Ambiental em São José do Rio Pardo - SP. Escola de Engenharia de São Carlos: USP, 2005. Dissertação de Mestrado. (Mestrado em Engenharia Florestal).

VASCONCELOS, R.N., BARBOSA E.C.C.; PERES, M.C.L. Borboletas do Parque Metropolitano de Pituaçu, Salvador: Bahia, Revista Sitientibus série Ciências Biológicas, v.9, 2009, p.158-164.

VASCONCELLOS, J.M.O. Interpretação ambiental. In: MITRUAD, S. (Org.). Manual de ecoturismo de base comunitária: ferramentas para um planejamento responsável. Brasília: WWF Brasil, 2003.

WAISMAN, L.; SHOCRON, M. Educar-Nos: nuevas propuestas para la educación y la convivencia.Buenos Aires: Lugar Editorial, 2001.

WEID, N.V.D. A Formação de professores em Educação Ambiental à luz da agenda 21. In: PÁDUA, S.M.; TABANEZ, M.F. (Ed.). Educação ambiental: caminhos trilhados no Brasil. Brasília: IPÊ, 1997.

WHITE, A.V.T. La perception de l' environment: lignes directrices méthodologiques pour lés etudes sur le terrain. Paris: UNESCO, 1978, 134p. 